\title{
ALGUMAS CONSIDERAÇÕES SOBRE A INTERFACE ENTRE A LÍNGUA BRASILEIRA DE SINAIS (LIBRAS) E A LÍNGUA PORTUGUESA NA CONSTRUÇÃO INICIAL DA ESCRITA PELA CRIANÇA SURDA
}

\author{
Renata Castelo Peixoto*
}

\begin{abstract}
RESUMO: O artigo propõe uma reflexão psicolingüística sobre as construções conceituais de crianças surdas no que diz respeito à escrita. O trabalho revela, a partir de um diálogo com as idéias de Emília Ferreiro e Ana Teberosky, que a psicogênese da escrita vivenciada por crianças surdas, que têm a língua de sinais como primeira língua e língua de instrução, se desenrola de forma diferente ao que é vivido por crianças ouvintes em processo inicial de construção da escrita. As principais especificidades dessa aquisição relacionam-se: a nãofonetização da escrita, a uma intensa exploração dos aspectos viso-espaciais da escrita e ao uso dos parâmetros fonológicos da língua de sinais como elemento regulador e organizador da escrita. Tais peculiaridades exigem, portanto, que a escola e o professor alfabetizador revejam suas concepçóes sobre o processo de escrita no surdo, pensando em (novas) práticas pedagógicas que considerem a realidade bilíngüe e sua relação não-sonora com a escrita.
\end{abstract}

Palavras-chave: Surdez. Psicogênese da escrita. Língua de sinais.

Considerations on the interface between the Brazilian Sign

Language (libras) and Portuguese language in the initial CONSTRUCTION OF WRITING OF DEAF CHILDREN

ABSTRACT: This paper proposes a psycholinguistic reflection on the conceptual constructions of deaf children in what regards writing. Based on a dialogue with the ideas of Emília Ferreiro and Ana Teberosky, this work reveals that the psychogenesis of writing experienced by deaf children who have sign language as their first and

\footnotetext{
* Mestre em Educação e psicóloga do Centro de Capacitação de Profissionais da Educação e de
} Atendimento às Pessoas com Surdez (CAS) - Ceará. E-mail: renatycp@ig.com.br 
Algumas consideraçôes sobre a interface entre a Língua Brasileira de Sinais (LIBRAS)...

instruction language, occurs in a different way than that of hearing children in the initial process of constructing writing. The main specificities of this acquisition are related to the non-phonetization of writing, to an intense exploration of the visual-spatial aspects of writing and to the usage of the phonologic parameters of sign language as a regulating and organizing element of writing. Such peculiarities thus demand that school and alphabetizing teachers revise their conceptions on the process of writing of the deaf, thinking of (new) pedagogical practices that take into account the bilingual reality and its soundless relationship to writing.

Key words: Deafness. Psychogenesis of writing. Sign language.

\section{Introdução}

$\mathcal{D}$

esde que se tornou evidente o fracasso das práticas oralistas em promover um aprendizado efetivo para o surdo, multiplicaramse em todo o mundo investigações das mais diversas ciências neurologia, psicologia, lingüística, educação - comprovando o valor das línguas de sinais e a influência positiva que elas têm na construção do desenvolvimento e da aprendizagem dessas pessoas. Os movimentos sociais organizados pelos surdos e essas - relativamente recentes - descobertas científicas funcionaram como questionamentos ao pensamento fonocêntrico que por tanto tempo orientou a educação para surdos, abrindo caminho para o rompimento com a visão de surdez como patologia e para o reconhecimento do surdo como sujeito bilíngüe.

Entende-se assim que, embora o surdo esteja inserido em uma sociedade e em um núcleo familiar cuja maior parte utiliza a língua oral majoritária, ele também está ligado - direta ou indiretamente - a espaços e pessoas que se comunicam por uma língua de sinais. Reconhecer, portanto, a condição bilíngüe do surdo implica aceitar que ele transita por essas duas línguas e, mais do que isso, que ele se constitui e se forma a partir delas. A língua de sinais, historicamente tão rechaçada, passa a ser percebida como parte positiva da vida do surdo, como elemento indispensável para garantir sua apropriação dos elementos culturais, de integração à sociedade e de acesso ao conhecimento - acadêmico ou não -, além de um bom desenvolvimento cognitivo e afetivo.

De fato, a língua de sinais, ainda que "proibida", jamais deixou de existir na vida do surdo, porém estava lá de forma tolhida, marginal, fora 
das salas de aula e de qualquer outro espaço "oficial" que o ouvinte tivesse (também) participação. A mudança de concepção em relação à surdez, a partir de uma visão interacionista, sócio-antropológica, devolve à sala de aula a língua "proibida" e, assim, instala condiçôes para que as práticas pedagógicas voltadas para o surdo sejam rediscutidas e redimensionadas, evoluindo para tornar-se um espaço mais dialógico, de produção e transmissão - de fato! - do conhecimento, de formação humana a partir do respeito e do reconhecimento positivo pela e da diferença.

É inegável a importância do retorno da língua de sinais aos espaços pedagógicos ocupados pelo surdo, respondendo e resolvendo antigas problemáticas que há muito obstacularizam a escolarização desses sujeitos. Mas é verdade também que novas questôes se colocam no cerne dessa discussão sobre a escola e a aprendizagem do surdo e que, evidentemente, mesmo não se caracterizando como um "problema", exigem da escola e dos pesquisadores novas reflexôes.

Reconhecer a condição bilíngüe do surdo é, portanto, apenas o começo de uma longa e intrigante travessia de descobertas e desafios. $\mathrm{O}$ acolhimento necessário e imprescindível da língua de sinais, como primeira língua do surdo e língua escolar, devolve ao surdo a esperança, ao mesmo tempo em que nos convoca a pensar sobre os processos e práticas construídos - agora - à luz dessa nova condição. A subjetividade do surdo e todos os processos relacionados a ela ganham novas nuanças, delineando-se talvez de forma diferente ao que supúnhamos acontecer quando a língua de sinais era - radicalmente - negada e as práticas pedagógicas eram, quase exclusivamente, mediadas pela língua oral. Se for modificada a forma do mundo interagir com o surdo, entende-se que também vão se alterar os modos como o surdo se relaciona com o mundo, nas apropriações e leituras que fará da realidade ao seu redor.

Dentre esses processos relacionados à escola e a aprendizagem, a escrita e a leitura parecem ser os que mais demandam essas novas reflexões, principalmente porque (e às vezes exclusivamente) é por meio desses dois processos que a condição bilíngüe do surdo se constrói e se revela. Uma criança surda, ainda que exposta intensivamente a interaçōes por meio da língua oral, pouco ou nenhuma apropriação fará dessa língua majoritária, porque está numa modalidade incompatível com sua realidade sensorial. Entretanto, quando essa mesma língua é apresentada em uma modalidade escrita, torna-se acessível às possibilidades visuais do surdo, favorecendo sua apropriação. 
Algumas consideraçôes sobre a interface entre a Língua Brasileira de Sinais (LIBRAS)...

Sendo a língua de sinais a primeira língua do surdo, é válido destacar que o encontro desses sujeitos com a escrita - da língua majoritária - é precedido e possibilitado pela língua de sinais. Quanto mais efetivo é o acesso da criança surda à língua de sinais, melhores chances ela tem de fazer uma apropriação mais consistente da escrita. Para grande parte dos surdos, a linguagem evolui através da língua de sinais, que amplia as possibilidades cognitivas e conceituais para nomear e categorizar a realidade ao seu redor, bem como perpassa os objetos de conhecimento com o qual se deparam. A escrita certamente é um desses objetos, particularmente importante, porque, como a língua de sinais, veicula conceitos que nomeiam a realidade; só que, ao contrário dessa última - e de qualquer outra língua não escrita - está "presa" ao papel, com menores possibilidades de contextualização natural. Portanto, embora a escrita também se constitua de signos que veiculam conceitos, materializa-se em um formato que dificulta a construção do sentido por ela mesma, sendo necessário buscar na língua não-escrita os elementos conceituais para atribuir sentido aos signos escritos. ${ }^{1}$

A língua de sinais instrumentaliza o surdo a interpretar e a produzir palavras, frases e textos da língua escrita, assumindo papel semelhante ao que a oralidade desempenha quando se trata da apropriação da escrita pelo ouvinte. A primeira língua de uma criança norteia, promove e facilita o acesso à escrita, e é justamente por isso que somos levados a pensar que surdos e ouvintes monolíngues terão vivências diferenciadas em relação à construção da escrita. Ao contrário do que acontece a esses últimos, os surdos não vão aprender uma escrita que intenciona representar a língua pela qual eles organizam a realidade. $\mathrm{O}$ processo de significação se daria da língua de sinais para a língua portuguesa escrita ao invés de ser da língua portuguesa oral para a língua portuguesa escrita.

Certamente nos dois casos são necessários ajustes às diferenças e às peculiaridades estruturais de cada uma dessas modalidades (oral x escrita e gestual x escrita). Entretanto, no caso dos surdos, essas diferenças se acentuam, pois não se restringem apenas à modalidade da língua e, sim, a própria língua. Conceituam e comunicam-se em uma língua, mas irão se alfabetizar em outra, diferente sintática, morfológica e foneticamente daquela pela qual eles lêem a realidade.

É em função disso que o acolhimento à condição bilíngüe do surdo exige da escola e dos pesquisadores novas reflexôes sobre os processos 
de leitura e escrita nesses sujeitos. Reconhecer que o surdo (precisa) partir da língua de sinais para chegar (mais eficazmente) à língua portuguesa é reconhecer também a inadequação do velho e conhecido discurso oralista - que situa(va) a produçâo de escrita dessas pessoas como "caótica", "incorreta" e fruto da "patologia do não ouvir". É também lançar um novo olhar sobre as irregularidades que costumam caracterizar os textos escritos desses sujeitos, considerando a sua diferença lingüística e, principalmente, a forma como a escola lida com essa diferença.

Nesse sentido, Fernandes (1999) e Adjuto (2001), investigando textos produzidos por adolescentes e adultos surdos, observaram que muitas das irregularidades morfossintáticas identificadas coincidiam com construções próprias da língua de sinais. O "equívoco" encontrava-se exatamente nos elementos textuais, cujo funcionamento era mais diferenciado de uma língua para outra, como, por exemplo, o uso dos artigos, dos conectivos em geral e a flexão de verbos e adjetivos.

Constatar esse atravessamento da língua de sinais na escrita da língua portuguesa nos permite ressignificar todas as adjetivações pejorativas que tradicionalmente são feitas à escrita dessas pessoas, especialmente, porque é possível observar que a mistura de parâmetros da primeira e da segunda língua não é um fenômeno que acontece exclusivamente com escritores surdos. A condição de segunda língua que o Português tem na vida do surdo promove nesse sujeito um estranhamento semelhante ao que nós, ouvintes, temos quando nos deparamos com uma língua estrangeira. Interpretar ou produzir uma escrita estranha à própria língua confronta nossa organização de linguagem e nosso conhecimento gramatical, exigindo uma produção de novas significações que só conseguiremos construir tendo como base a nossa língua materna.

O surdo, como qualquer sujeito bilíngüe, busca na língua que mais domina os elementos para significar a outra língua, o que produz uma inevitável e interessante aproximação entre as duas línguas. $\mathrm{O}$ encontro - ou melhor dizendo, "confronto" - entre as duas línguas é esperado e revela as riquezas, as especificidades que marcam o universo discursivo de sujeitos bilíngües. Sobre isso, Maher (1997) chama atenção para a relação conflitante e assimétrica que costuma caracterizar a existência das diferentes línguas na vida de sujeitos bilíngües diglóssicos, onde uma e outra disputam funçōes e posições na vida de seus usuários. No caso dos surdos, sensorialmente impedidos de ter acesso à língua 
Algumas consideraçôes sobre a interface entre a Língua Brasileira de Sinais (LIBRAS)...

portuguesa na modalidade oral, o "palco" dessa disputa será precisamente a escrita.

\section{Língua de sinais e a construção inicial da escrita da criança surda}

Perceber a realidade bilíngüe do surdo e entender que ele parte da língua de sinais para chegar à compreensão da língua portuguesa escrita ajuda-nos a repensar os processos de escrita e leitura em sujeitos surdos, mas não é esse o único elemento que deve ser considerado nessa reflexão. A especificidade lingüística do surdo também envolve o seu alheamento total ou parcial - à realidade sonora e a constatação de que a escrita chegará a ele mediada não apenas por outra língua, mas por uma língua que se compõe de elementos viso-espaciais e não-sonoros.

Certamente, não existe entre escrita e fala uma relação de identidade total e a evidência disso está em todas as irregularidades ortográficas de fonemas que têm mais de uma representação gráfica e de grafemas que têm como equivalentes mais de um som da fala, além de todas as peculiaridades prosódicas que denunciam quão diferente um texto falado pode ser de um texto escrito. Apesar disso, não podemos desconsiderar que fala e escrita são representaçôes de uma mesma língua e que existe uma intenção de que os elementos da escrita (letras) façam referências aos elementos da fala (fonemas). ${ }^{2}$

Do ponto de vista genético, a aproximação entre a oralidade e a escrita, embora não aconteça desde os estágios iniciais de (re)construção desse objeto - a escrita -, funciona como elemento alavancador do processo conduzindo a criança - ouvinte - a uma compreensão alfabética de escrita, permitindo-lhe fazer uso dessa pauta sonora para regular a sua produção escrita e a de outros. Segundo Ferreiro e Teberosky (1985), a partir de determinado momento do processo de construção conceitual da escrita (o denominado período silábico) a criança ouvinte passa a relacionar o que é escrito ao que é falado e essa compreensão lhe conduz a construir hipóteses que permitem prever, antecipar e corrigir suas escritas (a partir da oralidade).

Voltando nosso olhar à criança surda, surge, inevitavelmente, a indagação sobre o processo de reconstrução da escrita que ela vivencia, considerando especialmente a participação da oralidade nesse processo. Será que o som ou a referência visual dele - leitura fonoarticulatória - manifesta-se de alguma forma como mediação para a tarefa de escrever? 
Embora não seja negado que a oralidade se impõe à vida do surdo, por meio dos inúmeros interlocutores ouvintes e da infinidade de tecnologias e práticas reabilitadoras, como a prótese auditiva e a fonoterapia, não parece ser possível afirmar que essa oralidade seja usada, necessariamente, pela criança surda como forma de acesso à escrita. Ao contrário, conforme sugere o estudo de Machado (2000), crianças surdas com perda auditiva severa ou profunda não fonetizam a escrita, ou seja, não fazem qualquer regulação sonora - seja silábica, seja fonética desse sistema.

Segundo essa pesquisadora, as crianças surdas vivenciam um processo de (re) construção da escrita que, em muitos aspectos, é semelhante ao que é vivido pela criança ouvinte; ou seja, caminham de uma perspectiva inicial mais subjetiva, na qual a escrita não representa o nome das coisas e sim as próprias coisas, evoluindo para uma compreensão de escrita como representação da linguagem. Assim sendo, muitas das hipóteses infantis como o realismo nominal ou a exigência de variedade e quantidade de caracteres - que Ferreiro e Teberosky (1985) haviam identificado, quando os escritores em formação eram ouvintes, também apareceram nas crianças surdas pesquisadas por Machado (2000). Da mesma forma, a escrita inicial da criança surda se revelara mais instável quanto à relação significadosignificante e mais dependente do contexto e das imagens.

Apesar de todas essas coincidências psicogenéticas entre surdos e ouvintes, a evidência de que não acontecerá a fonetização da escrita pelo menos para boa parte dos surdos - constitui um diferencial importante e que precisa ser considerado para que possamos compreender a apropriação que a criança surda faz desse objeto. Isso é particularmente válido porque Machado afirma que, mesmo sem a fonetização, essas crianças evoluirão para uma compreensão de escrita alfabética, na qual se intenciona representar a linguagem (os "nomes") e não os objetos. Assim, chega-se a uma compreensão mais objetiva desse sistema, ou seja, existe uma maneira padrão de se grafar a palavra e, se alterarmos algo nos elementos que a compõem ou na ordem que esses elementos assumem, podemos alterar, também, o significado daquela palavra.

Para Machado, torna-se possível evoluir para uma compreensão alfabética (de escrita) mesmo sem a fonetização, porque este é também um sistema de organização viso-espacial. A natureza alfabética da nossa escrita apresenta uma organização linear, um espaço próprio com 
Algumas consideraçôes sobre a interface entre a Língua Brasileira de Sinais (LIBRAS)...

elementos que são visualmente percebidos. A criança surda, portanto, explora essa forma de organização e constrói estratégias que a permitem interpretar, produzir escritas, resguardando e respeitando esse funcionamento alfabético.

A exploração dos aspectos visuais da escrita parece ser (mesmo) um recurso fundamental no processo de apropriação desse sistema pela criança surda e nos ajuda a entender as especificidades que caracterizam essa aprendizagem. Entretanto, a compreensão que temos da realidade lingüística do surdo nos impulsiona a pensar que existem outras especificidades nesse processo.

Voltando a tematizar a condição bilíngüe do surdo, trazemos o questionamento a respeito do atravessamento da língua de sinais nas primeiras construções de escrita dessas crianças. Tal qual acontece com os surdos mais velhos, já leitores, produtores de escrita num âmbito formal, (ver Adjuto, 2001, e Fernandes, 1999), também para crianças em processo de alfabetização o percurso de significação da escrita se dá sobre as mesmas condiçôes de diálogo entre línguas. Para realizar um ato de leitura e/ou escrita da língua majoritária oral, a criança surda usa como referência a língua de sinais. Vivencia um processo semelhante ao de outras crianças bilíngües, já que, ao escrever, tem que dar não apenas uma significação ao grafismo, mas incorporar diferenças fonológicas, sintáticas e morfológicas nessa significação que será atribuída, caracterizando sua ação de leitor/escritor (também) como atos de tradução. Para a criança surda que se encontra diante da tarefa de alfabetizar-se o desafio é dobrado, pois não apenas precisa aprender a modalidade escrita de uma língua, mas também aprender a própria língua.

No caso das crianças surdas usuárias da língua de sinais, a busca de significaçóes na própria língua para produzir a escrita de uma outra língua é ainda mais complexa, se considerarmos a condição material da língua de sinais. As "palavras", nessa língua, não se constroem a partir de sons que se combinam, mas de mãos que se movimentam no espaço e que se organizam de forma simultânea e não-linear. Partir do corpo para chegar em letras que não intencionam representá-lo é certamente um diferencial importante na relação da criança com a escrita e que deve repercutir nas apropriações que esse sujeito fará desse objeto.

O reconhecimento truncado e tardio da condição bilíngüe do surdo nos coloca em uma situação ainda inicial de compreensão das 
especificidades que marcam a relação do surdo com a escrita. Certamente, a língua de sinais desempenha um papel nesse processo, cuja importância, embora já percebida, não foi nem devidamente e nem completamente detalhada pela psicolingüística, ou pela pedagogia.

Acolhemos os resultados dos estudos (Machado, 2000; Gesueli, 1998; Quadros, 1997) que apontam para o uso de estratégias de exploração dos elementos viso-espaciais da escrita como fator promotor do avanço nesse processo, mas entendemos também que apenas a utilização dessas estratégias não parece dar conta de todas as demandas que um escritor tem. Constantemente, nos deparamos com a tarefa de produzir escritas, cuja grafia padrão não nos é familiar, sendo necessário antecipá-la, predizer mentalmente como essa escrita será feita. Para os ouvintes, embora existam pistas contextuais (semânticas, pragmáticas) e gramaticais (conhecimento sobre formação de palavras; sufixos e prefixos que indicam determinadas categorias gramaticais), é por meio da fala que a grafia será prognosticada e, mesmo com as irregularidades entre fala e escrita, a criança conseguirá produzir um significante, pelo menos, semelhante ao esperado.

$\mathrm{O}$ que acontece, entretanto, quando essa mediação da fala não existe? Como é que uma criança surda pode prever a escrita de uma palavra nunca vista antes? Fundamentados em uma perspectiva construtivista, psicogenética, entendemos que qualquer criança, seja ela surda ou ouvinte, relaciona-se de forma ativa, construindo hipóteses sobre a realidade ao seu redor. Dessa forma, descartamos a possibilidade de que uma criança surda, ao se deparar com a escrita da língua portuguesa, não desenvolva idéias sobre esse objeto. A apropriação que uma criança faz da realidade em que transita é sempre uma ação inteligente, na qual ela estabelece comparaçôes e análises, o que nos leva a pensar que dificilmente a construção de uma escrita - mesmo que nunca vista antes - seja aleatória. Ao contrário, mesmo que divergindo de uma escrita padrão, essa refletirá as concepções e os conceitos que a criança pode construir sobre o "que" essa escrita representa e "como" se dá essa representação.

\section{A pesquisa}

Considerando que é através da mediação da língua de sinais que o surdo representa e conceitua à escrita, hipotetizamos que as teorias iniciais da criança sobre o que é escrita e como se dá essa representação 
Algumas consideraçôes sobre a interface entre a Língua Brasileira de Sinais (LIBRAS)...

fundamentar-se-ão também na língua de sinais. Intencionamos investigar a interface dessa língua (de sinais) com a língua portuguesa escrita ao longo do processo inicial, enfocando especialmente a construção do significante. Dessa forma, optamos pela elaboração de uma atividade de pesquisa para a qual a criança fosse convidada a escrever palavras correspondentes aos sinais que eram apresentados um a um. ${ }^{3}$

Como nosso interesse volta-se para as construçōes conceituais mais iniciais sobre a escrita, direcionamos a investigação para sujeitos que estão em processo de alfabetização e que ainda não são considerados pela escola como leitores/escritores, no sentido formal do termo.

Para tanto, foram entrevistadas 15 crianças com idades variando entre 4 e 11 anos e nível de escolaridade entre jardim e $2^{a}$ série. ${ }^{4}$ Todas são crianças surdas com perda auditiva severa ou profunda, ${ }^{5}$ estudantes de uma escola bilíngüe na cidade de Recife e que têm como professores profissionais surdos ou ouvintes usuários fluentes da LIBRAS, assegurando, assim, que a aprendizagem da escrita da língua portuguesa ocorra mediada pela língua de sinais.

A interação da pesquisadora com as crianças deu-se por meio da língua de sinais, o que significa que, para produzir a escrita pedida, a criança tinha como referência, ao invés de sons, uma ou mais de uma configuração de mão (CM) ${ }^{6}$ que realizava determinado movimento em uma região do corpo ou próximo a ele.

A fim de melhor compreender as estratégias de "tradução" da criança, apresentamos sinais com diferentes composiçōes (formaçôes):

a) por "inicialização": CM do sinal igual a CM da primeira letra da palavra correspondente;

b) por "empréstimo lexical": o sinal é quase uma soletração num ritmo alterado; ${ }^{7}$

c) por não fazer referência a nenhum empréstimo lingüístico e

d) por grupo de sinais compostos em dois (ou mais) radicais, cuja tradução na língua portuguesa é de uma palavra não-composta.

Procurando perceber as estratégias norteadoras para prever uma escrita, quando não se podem explorar os elementos e a organização espacial que eles assumem na grafia padrão, apresentamos às crianças, além de sinais familiares, cuja escrita provavelmente seria conhecida, 
também sinais familiares, cuja escrita não seria familiar e, ainda, um último grupo de sinais em que provavelmente nem a escrita e nem o próprio sinal eram conhecidos da criança. ${ }^{8}$ Segue abaixo a lista de palavras correspondentes aos sinais apresentados.

\begin{tabular}{|c|c|c|c|c|c|}
\hline & \multicolumn{5}{|c|}{ GRUPO 1: SINAIS E ESCRITAS FAMILIARES } \\
\hline & $\begin{array}{c}\text { Sinais } \\
\mathrm{c} / \text { inicialização }\end{array}$ & $\begin{array}{l}\text { Sinais cl } \\
\text { empréstimo } \\
\text { lexical }\end{array}$ & Sinais icônicos & $\begin{array}{c}\text { Sinais } \\
\text { compostos }\end{array}$ & $\begin{array}{c}\text { Outras } \\
\text { formações }\end{array}$ \\
\hline $\begin{array}{c}\text { Palavras } \\
\text { Monossílabas }\end{array}$ & “Flor" & "Pé” & “Eu” & & \\
\hline $\begin{array}{l}\text { Palavras } \\
\text { Dissílabas }\end{array}$ & "Brasil” & & & & $\begin{array}{l}\text { "Vêlh@/ } \\
\text { vovô/ó" }\end{array}$ \\
\hline $\begin{array}{l}\text { Palavras } \\
\text { Trissílabas }\end{array}$ & “Família" & & & "Escola" & "Recife" \\
\hline \multirow[t]{3}{*}{$\begin{array}{c}\text { Palavras } \\
\text { Polissílabas }\end{array}$} & "Matemática" & & & & \\
\hline & \multicolumn{5}{|c|}{ GRUPO 2: SINAIS FAMILIARES E ESCRITAS NÃO-FAMILIARES } \\
\hline & $\begin{array}{c}\text { Sinais } \\
\text { c/ inicialização }\end{array}$ & $\begin{array}{l}\text { Sinais cl } \\
\text { empréstimo } \\
\text { lexical }\end{array}$ & Sinais icônicos & Sinais compostos & Outras formações \\
\hline $\begin{array}{c}\text { Palavras } \\
\text { Monossílabas }\end{array}$ & & "Vez" & "Ver / olhar" & & “Mal” \\
\hline $\begin{array}{l}\text { Palavras } \\
\text { Dissílabas }\end{array}$ & "Piaui" & "Nunca" & & "Onça" & "Triste" \\
\hline $\begin{array}{l}\text { Palavras } \\
\text { Trissílabas }\end{array}$ & $\begin{array}{l}\text { "Maranhão" } \\
\text { "Roraima" } \\
\text { "Memória" }\end{array}$ & & $\begin{array}{l}\text { “Mastigar/ } \\
\text { chiclete" }\end{array}$ & "Madrasta” & $\begin{array}{l}\text { "Desculpe" } \\
\text { "Estória" }\end{array}$ \\
\hline \multirow[t]{3}{*}{$\begin{array}{l}\text { Palavras } \\
\text { Polissílabas }\end{array}$} & “Alívio/Aliviado" & & & & $\begin{array}{l}\text { "velocidade } \\
\text { /velozmente" } \\
\text { "Apartamento" }\end{array}$ \\
\hline & \multicolumn{5}{|c|}{ GRUPO 3: SINAIS E ESCRITAS NÃO-FAMILIARES } \\
\hline & $\begin{array}{l}\text { Sinais } \\
\text { c/ inicialização }\end{array}$ & $\begin{array}{l}\text { Sinais c/ } \\
\text { empréstimo } \\
\text { lexical }\end{array}$ & $\begin{array}{c}\text { Sinais } \\
\text { icônicos }\end{array}$ & Sinais compostos & Outras formações \\
\hline $\begin{array}{c}\text { Palavras } \\
\text { Monossílabas }\end{array}$ & & “Bar" & & & \\
\hline $\begin{array}{l}\text { Palavras } \\
\text { Dissílabas }\end{array}$ & "Derdic" & & & & $\begin{array}{l}\text { "Gat@" } \\
\text { "Azar" }\end{array}$ \\
\hline $\begin{array}{l}\text { Palavras } \\
\text { Trissílabas }\end{array}$ & $\begin{array}{c}\text { "Wisky" } \\
\text { "Social" } \\
\text { (ou "sociedade") }\end{array}$ & & & "Consertar" & $\begin{array}{l}\text { "Blasfemar" } \\
\text { "Depende" }\end{array}$ \\
\hline $\begin{array}{l}\text { Palavras } \\
\text { Polissílabas }\end{array}$ & $\begin{array}{l}\text { "Importado" } \\
\text { "Faculdade" } \\
\text { "Iguatemi" } \\
\text { "Lingüística" } \\
\text { "Filosofia" }\end{array}$ & & & & $\begin{array}{l}\text { "Qualidade" } \\
\text { "Psicologia" } \\
\text { "Filosofia" } \\
\text { (R)" }\end{array}$ \\
\hline
\end{tabular}

Cad. Cedes, Campinas, vol. 26, n. 69, p. 205-229, maio/ago. 2006

Disponível em <http://www.cedes.unicamp.br> 
Algumas considerações sobre a interface entre a Língua Brasileira de Sinais (LIBRAS)...

\section{Entre palavras e sinais: a escrita em questão}

Analisando a produção gráfica das 15 crianças, conseguimos perceber diferentes formas de apropriação desse sistema que, se por um lado coincidem com as construções conceituais já anunciadas pela psicogenética (ver Ferreiro \& Teberosky, 1985; Machado, 2000), por outro, nos apresentam novas e peculiares estratégias que revelam um funcionamento de escrita próprio a esses sujeitos bilíngües, não-ouvintes e usuários de uma língua viso-espacial.

Em um universo de crianças de 4 a 11 anos, cursando do jardim a $2^{a}$ série, apresentam-se diferentes níveis de domínio da língua de sinais e da língua portuguesa escrita, determinando, também, diferentes possibilidades de uso de uma ou outra língua como elemento de inspiração e apoio para as escritas a serem produzidas. Quanto maior é o domínio das duas línguas, mais significativa parece ser a análise, a comparação que a criança faz dessas línguas, encontrando elementos convergentes - ou não - que serão utilizados para nortear suas hipóteses.

Independentemente do grau de profundidade que essas análises assumem e da compreensão que a criança possui sobre "como" se dá a representação da escrita, foi percebido que a língua de sinais é usada como elemento de significação da escrita por crianças de todos os níveis conceituais, idades e séries. Mesmo nos estágios mais iniciais, onde a escrita - embora já esteja diferenciada do desenho enquanto forma gráfica de representação da realidade - busca ainda na imagem apoio e complementação do sentido, é possível perceber o atravessamento da língua de sinais.

É bem interessante observar nas produções de algumas das crianças mais novas que a primeira consideração feita ao significante sinalizado, quando existe uma demanda de escrita, manifesta-se de forma figurativa. E curioso, porém extremamente pertinente, já que as possibilidades conceituais dessas crianças sugerem o apoio da imagem e conduzem a uma produção de escrita em profunda sintonia com o desenho.

O desenho, como representação figurativa da realidade, é confortável para os escritores iniciantes, pois assegura a objetividade e a significação que sua escrita ainda não consegue passar. Apesar disso, é um recurso limitado - pois nem todos os conceitos podem ser desenhados que declina em grau de importância à medida que a criança percebe que 
a escrita é uma representação da linguagem, sendo seus elementos arbitrários diante do sentido que veiculam e autônomos em relação a qualquer elemento figurativo que os acompanhe.

A evolução no processo de construção da escrita conduz ao reconhecimento desse sistema como representação da linguagem, o que para uma criança ouvinte significa aproximar esse sistema da fala/oralidade.

Ao observar as construçôes de escrita de alguns dos sujeitos surdos dessa pesquisa, ficamos inclinados a pensar que a impossibilidade de traduzir em desenho todos os conceitos pedidos impulsiona essas crianças a buscarem também na linguagem as diretrizes para produzir sua escrita. A.D. (6 anos) e M.J. (5 anos), ambos da turma da alfabetização, produziram as primeiras escritas ("casa", "flor", "Brasil") acompanhadas da imagem do objeto ou de um símbolo correspondente a ele, de forma semelhante ao que acontece com crianças ouvintes.

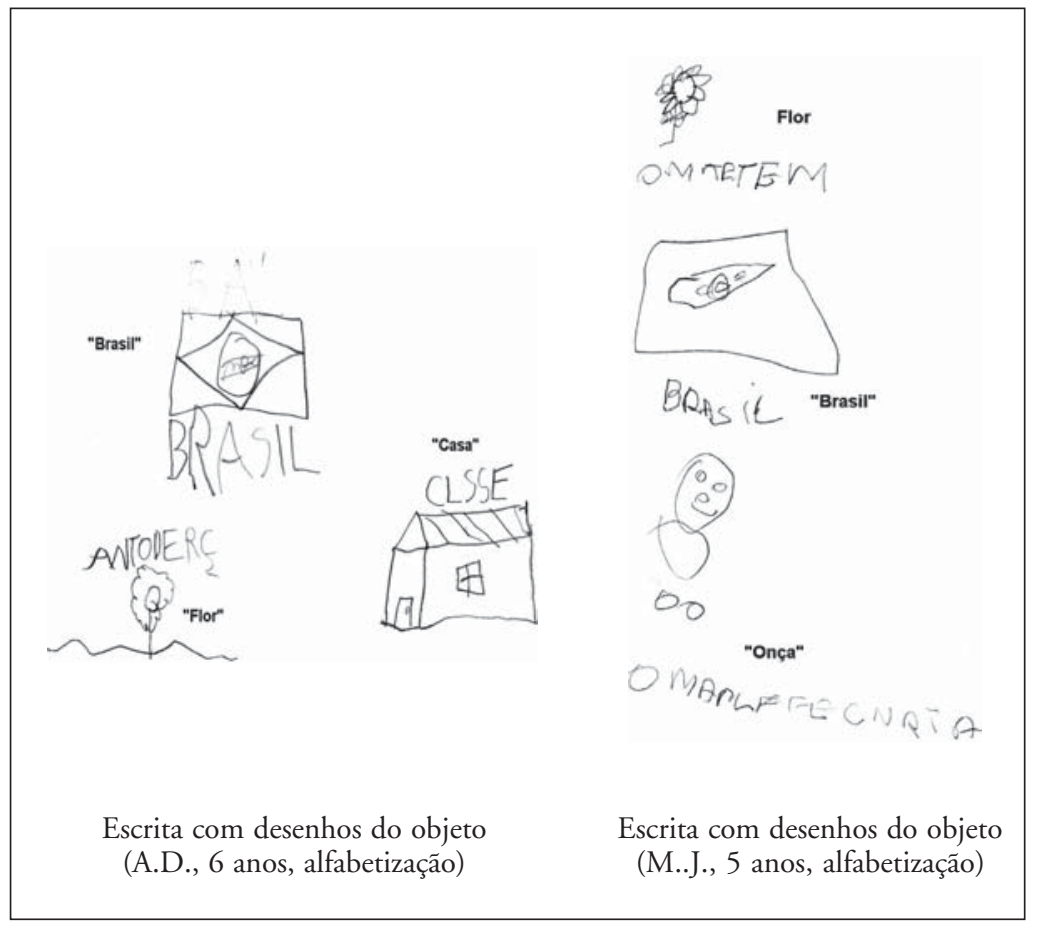


Algumas considerações sobre a interface entre a Língua Brasileira de Sinais (LIBRAS)...

Entretanto, quando se depararam com sinais cujo significado era desconhecido ou de difícil representação através do desenho, reestruturaram a imagem de forma que o que passou a ser desenhado foi o próprio sinal (rever).

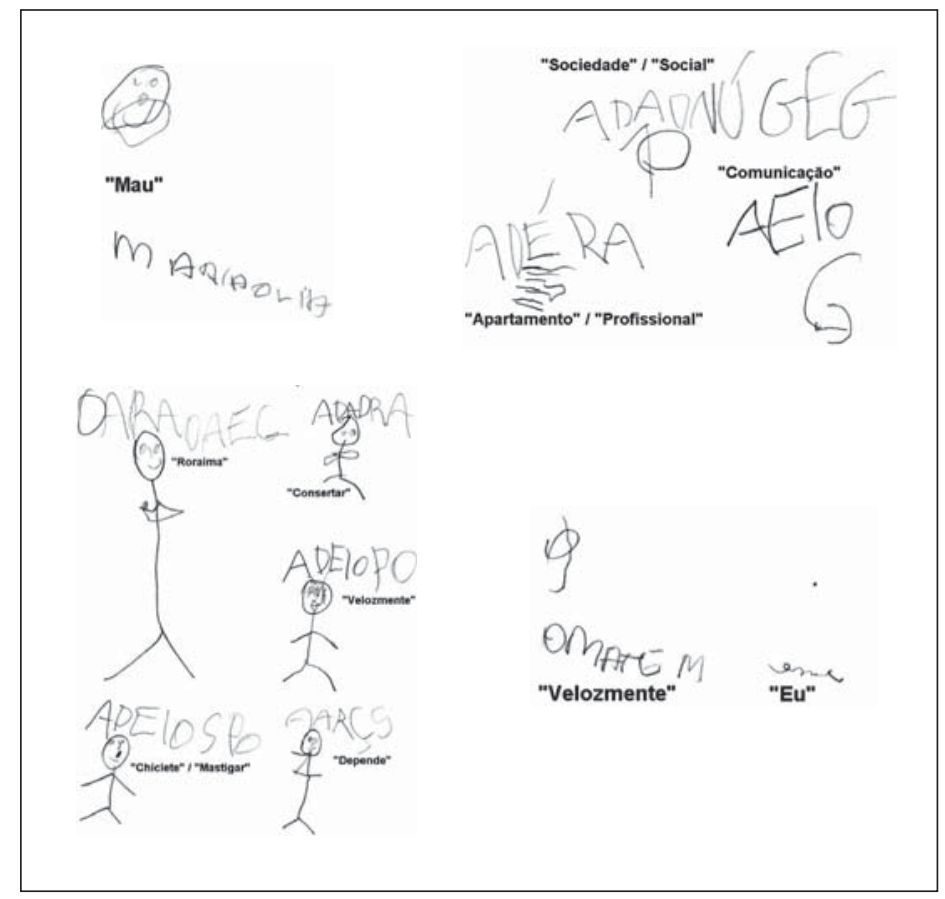

Escrita com o desenho do sinal de A.D. e M.J., alfabetização

Essa é certamente uma estratégia exclusiva da criança surda, já que a LIBRAS é uma língua visual e por isso pode ser, ao contrário de qualquer língua oral, "desenhada”, representada figurativamente. É também, inegavelmente, uma construção original, inteligente e que parece auxiliar a criança surda a perceber que a escrita se propõe a representar a linguagem - nome das "coisas" - e não a própria "coisa", já que, embora ainda recorra à imagem, passa a representar náo mais o significado e sim o significante. 
Transformar a escrita em representação da linguagem é, sem dúvida, uma evolução, um avanço em direção à compreensão formal, alfabética da escrita. Neste caso, porém, o significante que foi representado não corresponde àquele que nossa escrita se propõe a registrar, já que faz referência à LIBRAS e não à língua portuguesa. Imaginamos que, para uma criança surda em processo de construção inicial da escrita, não exista a compreensão de que a escrita que está ao seu redor e que demanda que ela aprenda não faz referência à língua pela qual ela nomeia a realidade. ${ }^{9}$ Essa consciência, se existir, será posterior. Entretanto, mesmo uma criança surda usuária da língua de sinais convive e interage cotidianamente com representações de escrita da língua portuguesa espalhadas por todos os lugares, nos mais diferentes tipos de portadores de texto (cartazes, letreiros, jornais, livros, rótulos etc.), o que lhe permite chegar também à compreensão de que, se a tarefa é "escrever", alguma referência a esse sistema de letras que se organizam linearmente terá que ser feita.

Talvez, por isso, todo o restante de estratégias que identificamos nessas 15 crianças faz, de alguma forma, referência aos elementos da língua portuguesa escrita. Abandonar uma concepção de escrita que registra exclusivamente os elementos da língua de sinais não quer dizer, entretanto, que essa língua deixará de nortear as produçōes escritas da criança surda, ao contrário, ela estará bem presente, marcando de diferentes formas essa escrita. A língua de sinais continuará sendo apoio, lugar de reflexão e de atribuição de sentido ao texto que será escrito, à diferença de que agora não vai haver uma "escrita" dos sinais, mas uma escrita com os sinais, onde a palavra escrita é, na maioria das vezes, resultado de um diálogo (ou, porque não dizer, confronto) ${ }^{10}$ entre os elementos e as características dos dois sistemas, das duas línguas.

A idéia de que existe uma relação entre escrita e linguagem conduz sujeitos surdos e ouvintes a estabelecer correspondências entre o que é "falado" - sinalizado - e o que é escrito. Isso parece ser especialmente válido quando é necessário produzir uma escrita para sinais cujo significado é desconhecido ou ainda quando não se conhece a grafia padrão equivalente a esse sinal. Em várias das escritas das crianças pesquisadas, observa-se que a palavra escrita, embora não tivesse nenhuma - ou quase nenhuma - semelhança ortográfica com a escrita correta, fazia referência a outro(s) sinal(is) fonologicamente semelhante(s) ao sinal apresentado. Vejamos alguns exemplos: 


\section{Exemplo 1}

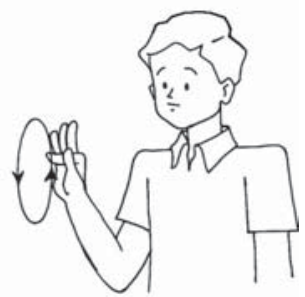

Sinal apresentado ("Faculdade")

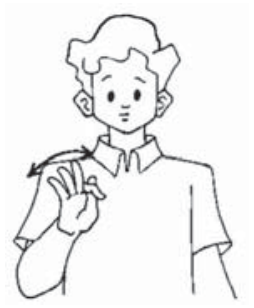

Respostas escritas das crianças: "Fevereiro" - Y. 2as. e "Fevebro" - Ar, 2as.

\section{Exemplo 2}

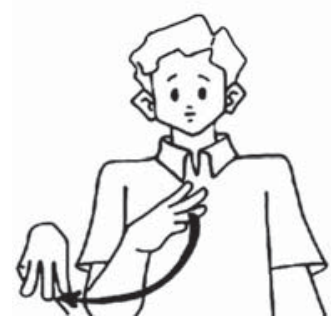

Sinal apresentado (“Maranhão")

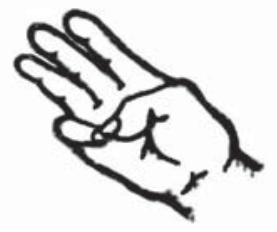

Resposta escrita da criança: "três" - Y. 2a série

Não conhecer o significado do que precisa ser "grafado" parece ser desconfortável e contrariar a natureza da leitura e da escrita (Smith, 1989). Se o significado não está dado, ${ }^{11}$ busca-se no significante uma forma de chegar o mais próximo dele. Neste caso, escolheu-se um sinal que tem um ou mais dos parâmetros fonológicos iguais, ${ }^{12}$ preferencialmente aquele cuja escrita padrão, equivalente na língua portuguesa, já fosse familiar e produziu a escrita equivalente a esse sinal.

É interessante observar que a comparação que a criança estabeleceu entre os dois significantes sinalizados não desconsidera as diferenças - mesmo que só as perceba após a intervenção da pesquisadora - e que isso é 
transposto para a escrita. Se há apenas uma pequena diferença no nível fonológico dos sinais (por exemplo, a configuraçáo da mão de apoio e o movimento em relação aos sinais "centro" e "importação"), é razoável que exista apenas uma pequena diferença ortográfica (como, por exemplo, o " $\mathrm{s}$ " acrescentado à palavra "centro" para representar o sinal "importação").

É possível, ainda, perceber a relação que a criança estabelece entre aspectos fonológicos do signo "falado" e aspectos ortográficos do signo escrito, mesmo quando as escritas produzidas são aparentemente aleatórias, ou seja, completamente divergentes da ortografia de uma escrita correta - mesmo que equivalente a outro sinal.

Exemplo 1: Ab. 2a série

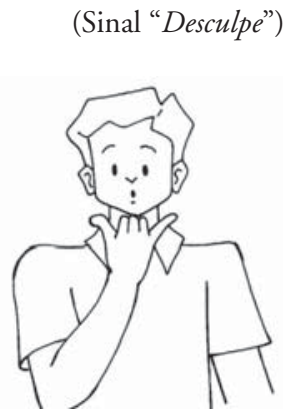

Escrita produzida: "IES" $\mathrm{x}$

(Sinal "Depende")

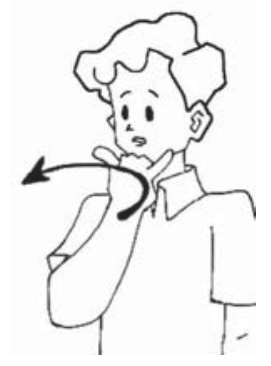

"IESON"

Exemplo 2: Am. 2a série

(Sinal "Filosofia")

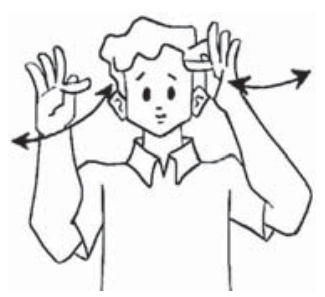

Escrita produzida: "FVANO" $\mathrm{x}$

(Sinal "Faculdade")

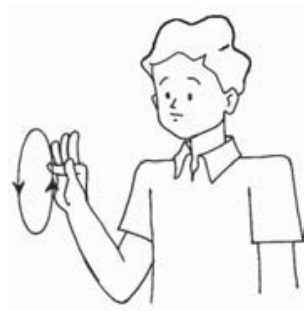

"FANO"

Disponível em <http://www.cedes.unicamp.br> 
Algumas consideraçôes sobre a interface entre a Língua Brasileira de Sinais (LIBRAS)...

Da mesma forma, observou-se essa lógica conduzindo a escrita de sinais que são compostos - ou seja, possuem dois ou mais radicais -, mas que, quando são traduzidos para a língua portuguesa, apresentam apenas um radical. Diversas crianças produziram escritas com dois ao invés de apenas um radical.

Sinal apresentado: "Consertar"
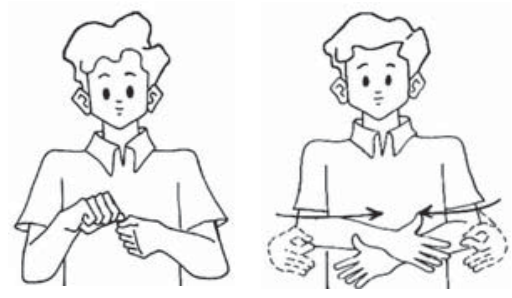

Escritas produzidas:

"Vis Sis" (ab. 2a série)

"Fazo esspiuv" (Li. 2a série)

"Fez, maisno" (Y. 2a série)

Desde o início, o processo de (re)construção da escrita, pelo qual passa a criança surda, revela a existência de um sujeito ativo que analisa, compara com lógica e complexidade os elementos das duas línguas pelas quais transita. Partir de um sinal para chegar a uma palavra é propor inevitavelmente uma aproximação entre as duas línguas, um confronto entre letras, linearidade, mãos, movimento e espaço. A familiaridade maior certamente é com a língua de sinais, o que faz com que a criança busque no significante dessa língua elementos para construir a escrita. Apesar disso, a língua portuguesa se apresenta, impondo seu funcionamento, suas regularidades, convocando os pequenos escritores a incluí-la em sua pauta de reflexões. Como resultado deste "embate", o que aparece é um sujeito cuja maior parte das estratégias para escrever considera igualmente os parâmetros do sinal e da escrita e busca elementos comuns entre eles.

Mas existirão esses pontos comuns? Quais seriam, do ponto de vista da criança surda, os espaços de interface da Língua Brasileira de Sinais com a Língua Portuguesa? Os pontos comuns existem sim, não apenas do ponto de vista da criança, mas como interface real das duas línguas. Parecem ser dois os principais elementos de aproximação: um primeiro seria o alfabeto digital, a transformação das letras do alfabeto da língua portuguesa - e que, portanto, compõe a escrita - em configuração de 
mão. Ou seja, um parâmetro que é próprio da língua portuguesa (a letra) se converte em um parâmetro formador da língua de sinais (a CM).

É interessante esclarecer que não é exatamente o alfabeto digital, enquanto soletração das palavras, que é usado pelas crianças como estratégia de chegar até a escrita. Ocasionalmente, muitas das crianças usam da datilologia antes de ler ou escrever uma palavra, mas, independente disto ocorrer ou não, existe a compreensão de que 26 das 46 configurações de mão que elas usam - não para soletrar, mas para compor o sinal - podem ser convertidas em letras e isso é considerado quando, diante de um sinal, ela precisa produzir uma escrita.

O outro elemento, que possibilita interface das duas línguas, está nos empréstimos lingüísticos que existem na LIBRAS. Esse, que é um recurso presente não só na LIBRAS, mas em diversas outras línguas, reflete o trânsito lingüístico de seus usuários, que utilizam elementos pertencentes à outra(s) língua(s) que, mesmo sendo "estrangeiras", participam significativamente da vida daquela comunidade para compor sua própria língua.

No caso dos empréstimos da LIBRAS, os elementos apropriados são obviamente da língua portuguesa ou de outras línguas de sinais (Ferreira Brito, 1995). Aqui, gostaríamos de destacar dois desses empréstimos

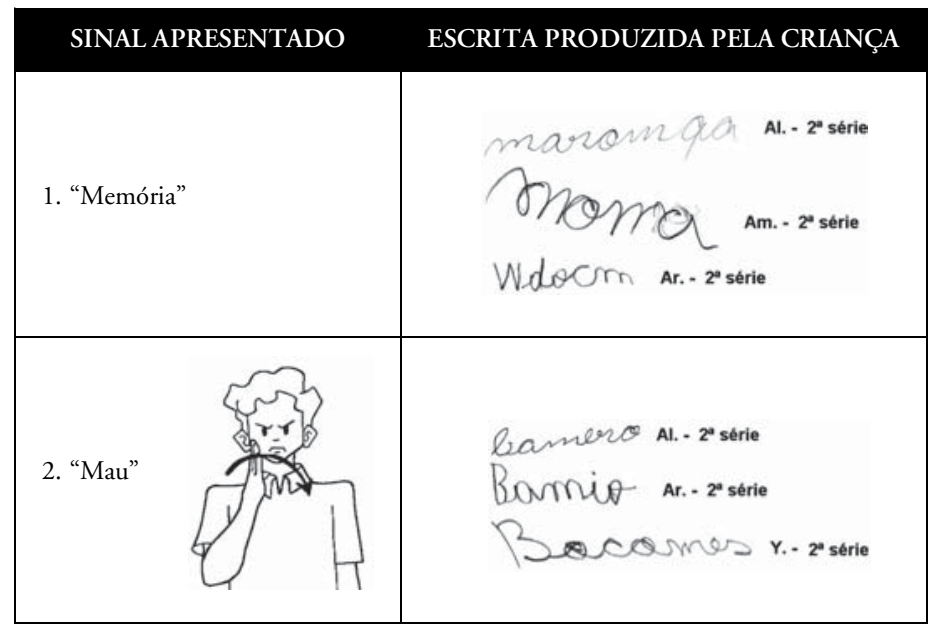

Configuração de mão do sinal utilizada como primeira letra e o restante da palavra apresenta leve ou nenhuma semelhança com a escrita correta. 


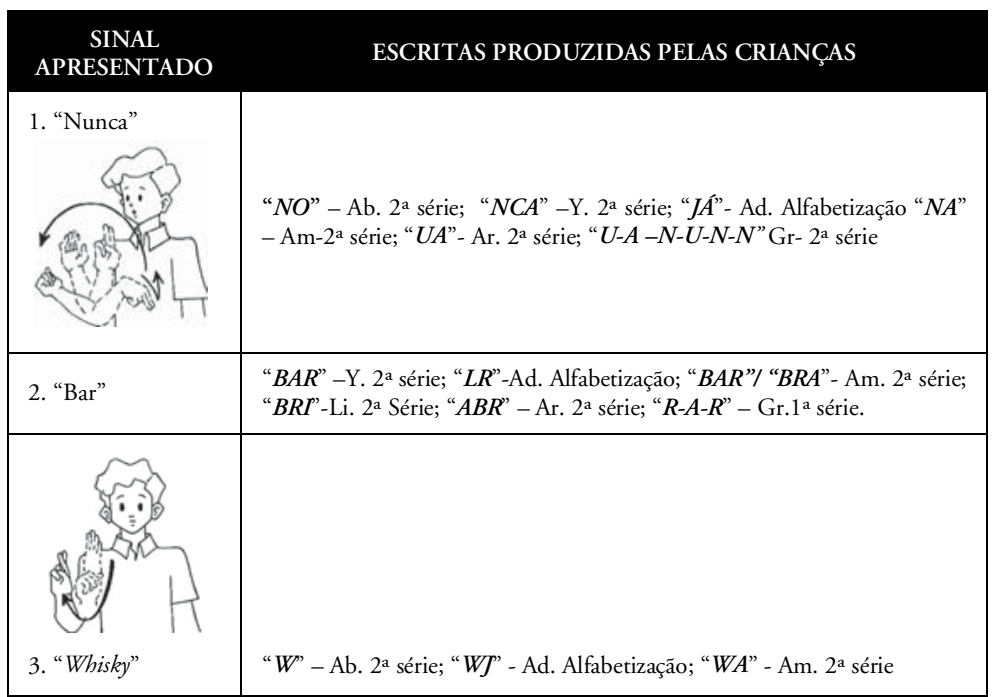

A escrita é uma apropriação direta do que a criança percebe como sendo a CM do sinal

lingüísticos que estão diretamente ligados ao elemento de intercessão das duas línguas (o alfabeto digital citado a pouco): o "empréstimo lexical" e a "inicialização". Nessas duas formas, o sinal é formado levando-se em consideração a primeira ou todas as letras que compõem a palavra correspondente a ele, sendo mais uma vez as letras - parâmetros próprios à escrita convertidas em configurações de mão - parâmetros próprios à língua de sinais.

Nesse sentido, observou-se que em um terço de todas as produçōes das 15 crianças pesquisadas aparece o uso dessa estratégia de converter a(s) configuração(ções) de mão do sinal apresentado em uma (a primeira) ou mais letras da palavra a ser produzida.

Um último exemplo é especialmente ilustrativo desse movimento da criança surda em correlacionar dois sistemas, buscando aproximar os dois significantes, ainda que as possibilidades de "transcrição" sejam reduzidas. Diante do sinal "Iguatemi" - cujo significado é desconhecido, já que é um sinal utilizado apenas em Fortaleza -, algumas crianças não apenas converteram a $\mathrm{CM}[\mathrm{I}]^{13}$ na letra "i” (o que é possível pois a letra "i" tem como representação no alfabeto digital essa $\mathrm{CM}$ ), como também 
tentaram transformar a segunda CM [5] em letra, mesmo não sendo ela equivalente a nenhuma das 26 letras do alfabeto digital. Comparando a produção de três crianças abaixo, tem-se a impressão de que a conversão foi motivada pelo conjunto $\mathrm{CM}+$ movimento de tamborilar os dedos, que parecem se assemelhar a um "m" em cursiva.

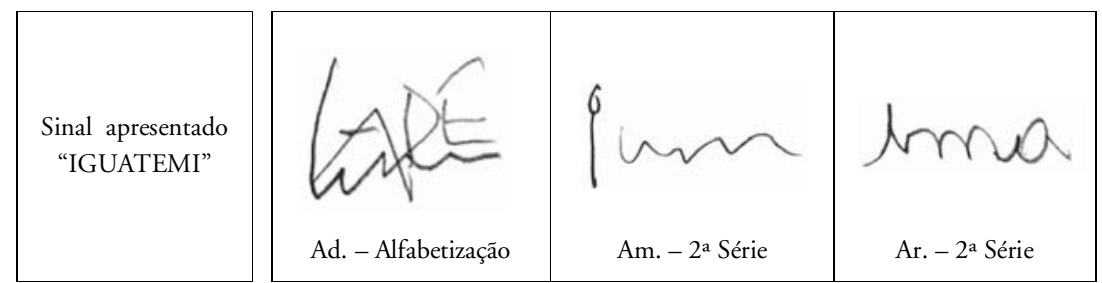

Escritas para o sinal "Iguatemi"

\section{Considerações finais}

O retorno da língua de sinais à realidade social do surdo, especialmente aos espaços pedagógicos destinados a ele, tem não apenas possibilitado transformações nas condições de desenvolvimento e aprendizado desses sujeitos, como também aberto condiçōes para que sua realidade bilíngüe e sua especificidade lingüística entre oficialmente na pauta das reflexōes obrigatórias sobre a educação de surdos. Nesse sentido, voltamos nosso olhar para o polêmico, controverso e intrigante tema da escrita com a modesta intenção de perceber elementos que, até então, com a nossa fonocêntrica perspectiva, não foi possível alcançar.

A confirmação da imprescindibilidade da língua de sinais no processo de construção de escrita do surdo é certamente o primeiro - e mais evidente - resultado que essa investigação sugere e que não poderíamos deixar de explicitar. A língua de sinais participa desde o início desse processo, mediando a relação entre a criança e a escrita, funcionando como apoio e lugar de reflexões sobre esse novo objeto do conhecimento, de forma semelhante ao papel que a oralidade exerce quando esse processo é vivenciado pela criança ouvinte.

Parece ser por meio da língua de sinais, assim como da análise dos aspectos viso-espaciais da escrita, que a criança surda constrói os caminhos que, substituindo a fala, lhe conduzem a uma compreensão mais 
Algumas consideraçôes sobre a interface entre a Língua Brasileira de Sinais (LIBRAS)...

avançada do sistema de escrita. ${ }^{14} \mathrm{~A}$ análise da escrita aproxima esta criança das regularidades desse sistema, mas apenas isto não parece ser o suficiente para prever, antecipar escritas nunca vistas antes.

É por meio da língua de sinais, dos seus parâmetros de composição - especialmente da configuração de mão - que essa predição tornase possível. Em seu processo de (re)construção da escrita, a criança surda analisa, disseca o significante sinalizado, estabelecendo comparaçōes com o significante escrito e buscando elementos comuns entre eles.

$\mathrm{O}$ escritor surdo não (parece) estabelece(r) a relação entre o que se fala e o que se escreve, mas consegue, através da mediação da língua de sinais, superar uma perspectiva inicial mais global, na qual a escrita é vista como uma representação dos objetos, e chegar a uma compreensão de escrita como representação da linguagem.

Essa é uma evolução conceitual importantíssima. Apesar disso, não podemos deixar de considerar que essa representação não fará referência à língua de sinais. A língua escrita que surdos e ouvintes aprendem corresponde a uma representação gráfica da língua majoritária oral. Por isso, torna-se importante que a escola promova uma ação pedagógica capaz de favorecer a compreensão de que escrita e sinais não são apenas modalidades diferentes de uma mesma língua, mas, sim, línguas diferentes com organizaçôes morfológicas e fonológicas diferenciadas.

Não há duvida de que a língua de sinais sempre funcionará para o surdo como o lugar de sentido e de reflexão sobre a escrita, mas uma adequada intervenção pedagógica deve ser capaz de contribuir para que as diferenças entre as línguas sejam percebidas e para que o surdo possa produzir uma escrita que respeite as regularidades da língua portuguesa.

Da mesma forma, é fundamental que a escola e os educadores possam perceber a escrita do surdo à luz de todas as especificidades que marcam essa construção. A ausência da regulação oral e o atravessamento da língua de sinais conduzem à construção de hipóteses diferentes daquelas já bem conhecidas pelo professor alfabetizador. Ignorá-las seria perpetuar a concepção equivocada cujas diferenças, que se manifestam na escrita do surdo, são sempre interpretadas como caóticas e aleatórias, reforçando assim injustamente a imagem de péssimos escritores. Há lógica e regularidade na escrita inicial da criança surda, mas essa não é uma lógica sonora e isso, certamente, se choca com as práticas alfabetizadoras ainda tão arraigadas à idéia de que para escrever é preciso falar. 
As dificuldades que o surdo apresenta em relação à produção e interpretação de texto certamente apontam para a relação diferente que ele tem com a língua portuguesa, mas, principalmente, parecem ser conseqüência das limitações da escola em lidar com essa diferença. Apesar de todos os fracassos, muitas escolas ainda insistem em alfabetizar o surdo nos mesmos moldes do que fazem com o ouvinte, utilizando a fala, o som como pauta de compreensão da escrita, estabelecendo formas de análise do texto e da palavra a partir de unidades da fala. Os surdos, na sua grande maioria, não fonetizam a escrita, o que torna todas essas estratégias inócuas e confirmam a inadequação de se ter procedimentos metodológicos que preconizam o (bom) desempenho oral como requisito indispensável à alfabetização.

Recebido em outubro de 2005 e aprovado em fevereiro de 2006.

Notas

1. A autonomia que a escrita adquire como lugar de representação e atribuição de sentido não é negada. Entretanto, no processo inicial de aquisição, a escrita, conforme afirma Vigotski (1991), constitui-se de um sistema de símbolos e signos de segunda ordem e precisa da linguagem não-escrita como "elo" entre ela e a realidade. A internalização demanda, necessariamente, operaçôes mentais mediadas por signos, e a linguagem é o sistema semiótico mais privilegiado para fazer essa mediação.

2. Isso é válido para as escritas alfabéticas das civilizaçôes ocidentais, como é o caso da escrita da língua portuguesa.

3. A realização dessa atividade foi parte das investigaçôes referentes à pesquisa de mestrado da autora (ver Peixoto, 2004).

4. Foram apenas 1 criança de jardim ( 4 anos) e duas - de 5 e 6 anos - de alfabetização. $\mathrm{O}$ restante tinha entre 7 e 11 anos e estavam distribuídas na $1^{\text {a }}$ e $2^{\text {a }}$ séries.

5. Interessa-nos compreender que recursos são utilizados para substituir o som/fala na regulação da escrita. Crianças com perda leve ou moderada poderiam vir a fonetizar a escrita.

6. São 3 os principais parâmetros de composição do sinal: a configuração de mão (CM), o ponto de articulação (PA) e o movimento (M).

7. Sobre a forma de composição dos sinais e empréstimos da LIBRAS, consultar Ferreira Brito (1995).

8. Para isso, selecionamos sinais regionais de outros estados que não eram utilizados em Recife, bem como sinais técnicos.

9. Alias, conforme sugere Góes (1999), mesmo em surdos adultos já alfabetizados não parece existir compreensão de que escrita e língua de sinais não são apenas modalidades diferentes, mas também línguas diferentes. Essa é uma compreensão metalingüística, que certamente não se dá espontaneamente, mas na medida em que a escola orienta suas práticas pedagógicas para promover sua compreensão. 
Algumas considerações sobre a interface entre a Língua Brasileira de Sinais (LIBRAS)...

10. Segundo Maher (1997), a relação diglóssica é conflituosa e assimétrica e há sempre uma língua dominante tentando enfraquecer e "abocanhar" funções próprias da língua dominada, o que certamente desencadeará essa posição de defesa e resistência da língua dominada. Certamente, para o surdo que vivencia o bilingüismo diglóssico, a escrita vai se constituir como lugar privilegiado de encontro da Língua Portuguesa (dominante) e Língua Brasileira de Sinais (dominada) e, portanto, também de confronto.

11. É o que parece ter acontecido nos exemplos 1, pois "faculdade", como foi mostrado, é referente ao léxico da língua de sinais de Fortaleza.

12. Como, por exemplo, em "memória" e "terça-feira", em que os dois sinais têm a mesma CM, o mesmo PA e o mesmo movimento (M), diferindo apenas por um parâmetro secundário que é a orientação da palma da mão, já que um está voltado para fora ("terça”) e a outra para baixo ("memória”).

13. O sinal "Iguatemi" consiste nas CM [I] seguido da configuração [5]. É realizado no espaço neutro (diante do tórax) e, quando a mão está com a configuração [5], realiza um movimento de tamborilar os dedos.

14. Confirmando o estudo de Machado (2000), também não identificamos em nossos sujeitos qualquer evidência de fonetização da escrita. Mesmo as crianças que conseguiam oralizar alguns dos sinais apresentados não faziam uso dessa competência no momento de produzir a escrita, confirmando que não parecer ser mesmo este - o som - o caminho mais confortável.

\section{Referências bibliográficas}

ADJUTO, E.F. O papel desempenhado pela lingua brasileira de sinais na produção escrita de alunos surdos. 2001. Dissertação (Mestrado) - Faculdade de Educação, Universidades Estadual de Campinas, Campinas.

FERNANDES, S. É possível ser surdo em português? Língua de sinais e escrita: em busca de uma aproximação. In: SkLIAR, C. (Org.). Atualidade da educação bilíngüe para surdos. Porto Alegre: Mediação, 1999. v. 2, p. 59-81.

FERREIRA BRITO, L. Por uma gramática de língua de sinais. Rio de Janeiro: Tempo Brasileiro, 1995.

FERreiro, E.; TEBerosky, A. Psicogênese da língua escrita. Porto Alegre: Artes Médicas, 1985.

GESUELI, Z.M. A criança surda e o conhecimento construído na interlocução em lingua de sinais. 1998. Tese (Doutorado) - Faculdade de Educação, Universidade Estadual de Campinas, Campinas.

GÓES, M.C. Linguagem, surdez e educação. Campinas: Autores Associados, 1999. 
MACHADO, E.L. Psicogênese da leitura e da escrita na criança surda. 2000. Tese (Doutorado) - Pontifícia Universidade Católica de São Paulo, São Paulo.

MAHER, T.M. O dizer do sujeito bilíngüe: aportes da sociolinguística. In: SEMINÁRIO DESAFIOS E POSSIBILIDADES NA EDUCAÇÃO BILÍNGÜE PARA SURDOS, 1997, Rio de Janeiro. Anais... Rio de Janeiro: Líttera Maciel, 1997. p. 20-26.

QUADROS, R.M. A aquisição de L1 e L2: o contexto da pessoa surda. In: SEMINÁRIO DESAFIOS E POSSIBILIDADES NA EDUCAÇĀO BILÍNGÜE PARA SURDOS, 1997, Rio de Janeiro. Anais... Rio de Janeiro: Líttera Maciel, 1997. p. 80-85.

PEIXOTO, R.C. A interface entre a Lingua Brasileira de Sinais (LIBRAS) e a Lingua Portuguesa na psicogênese da escrita na criança surda. 2004. Dissertação (Mestrado) - Universidade Federal do Ceará, Fortaleza.

SMITH, F. Compreendendo a leitura: uma análise psicolingüística da leitura e do aprender a ler. Porto Alegre: Artes Médicas, 1989

VIGOTSKI, L. S. A formação social da mente. São Paulo: Martins Fontes, 1991. 